\title{
Design of A Setup of Cvd* For Cnt Synthesis and Study of Properties of Cnts Reinforced With Aluminium Based Composites
}

\author{
Jeetendra Kumar ${ }^{1}$, Sumit Kumar Mahato ${ }^{2}$, Deendayal Singh Yadav $^{3}$ \\ ${ }^{1,2,3}$ Dept. of Mechanical Engineering Shri Mata Vaishno Devi University Katra, Jammu, 182320, India
} (Student)

\begin{abstract}
The physics of Carbon Nanotubes has rapidly evolved into a research field since their discovery by lijima [4] in multiwall form in 1991. In this research we have attempted an approach to obtain homogeneously dispersed CNTs in Al powders for preparing Al/CNTs nanocomposite. Ball milled Al and CNTs mixture has been compacted by universal testing machine under the load of 3 tons. Micro hardness and relative density of compacted composites of different weight percentage ratio of CNTs has been measured. By using Vicker hardness test, Optical Microscope, Scanning Electron Microscope (SEM) techniques we analyzed the hardness, micro structures and grain boundaries of casted Al-CNTs composites and compared the hardness of pure Al and CNTs reinforced Al composites at different weight percentages of CNTs. Also we checked the mixing pattern of Al CNT composites using X-Ray Diffraction (XRD) technique.
\end{abstract}

Keywords: Carbon Nanotubes (CNTs); *Chemical Vapour Deposition (CVD); Al CNTs Composites; X-Ray Diffraction; Hardness.

\subsection{Carbon Nanotubes (Cnts)}

\section{Introduction}

Carbon nanotube is a graphene sheet appropriately rolled into a cylinder of nanometer size diameter. The bonding between carbon atoms is in $\mathrm{sp}^{2}$ and $\mathrm{sp}^{3}$ configurations. The c-c covalent bonding and seamless hexagonal network architecture gives high strength and flexibility [1].

\subsection{Types of CNTs}

Carbon nanotubes are usually found two forms [Ref. Fig1]

1. Single walled carbon nanotubes (SWCNTS)

2. Multi walled carbon nanotubes (MWCNTS)

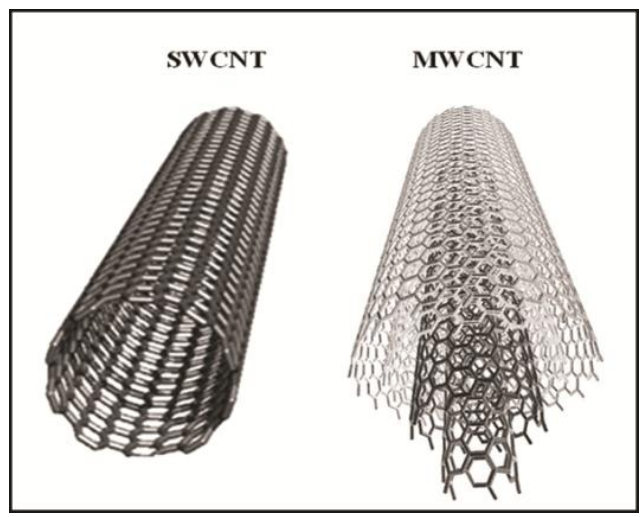

Fig. 1: Types of CNTs[1]

Structure plays a vital role in determining its properties. CNT is nothing but a rolled sheet of graphene. A Graphene sheet consists of a layer of carbon atoms, in this graphene layer, the atoms are strongly (covalent) bonded to each other with a C-C distance $-0.34 \mathrm{~nm}$.

SWCNTs are considered to be a rolled single sheet of graphene. Graphene sheets are seamless cylinders derived from honeycomb lattice, representing a single atomic layer of crystalline graphite [Ref. Fig. 2]. SWCNTs are considered as cylinders with only one wrapped graphene sheet and are completely described by a single vector C (chiral vector)

$$
\mathrm{C}=\mathrm{na}_{1}+\mathrm{ma}_{2}
$$

Where, $n \& m$ are integer, $a_{1} \& a_{2}$ are unit vectors. The direction of nanotube axis is perpendicular to this chiral vector [23]. 


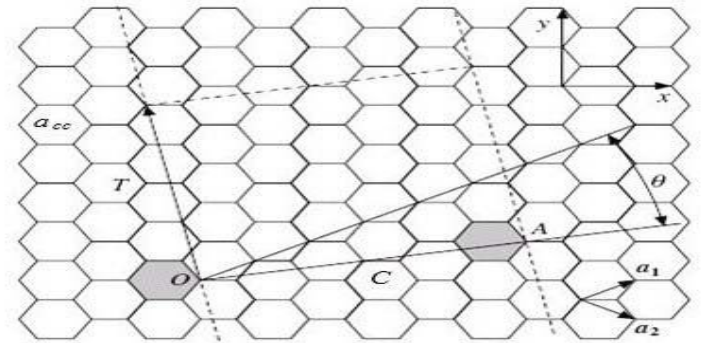

Fig.2. Construction of graphene sheet and important parameters for CNTs [23]

MWCNTs are collection of concentric SWCNTs. It may be formed from cylindrically curved graphene sheets stacked up concentrically. [Ref. Fig3].

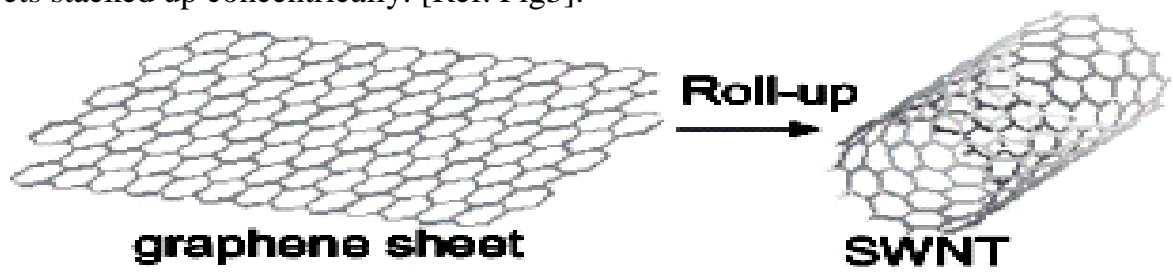

Fig.3- Rolling of graphite sheet into a SWCNT [1]

The length of the chiral vector $\mathrm{C}$ is circumference of the nanotube and is given by the relation $\mathrm{C}=\mathrm{a}\left(\mathrm{n}^{2}+\mathrm{nm}+\mathrm{m}^{2}\right)^{1 / 2}$

In case of SWCNTs, three types of nanotubes exist [Ref. Fig.3]. They are classified on the basis of the pair of integers $(n, m)$ which are related to the chiral vector-

(a) When $\mathrm{n}=\mathrm{m}$, the nanotube is called "Arm Chair" type $\left(\mathrm{Y}=0^{\circ}\right)$.

(b) When $\mathrm{m}=0$ then it is "zig zag" type $\left(\mathrm{Y}=30^{\circ}\right)$ otherwise,

(c) When $\mathrm{n} \# \mathrm{~m}$, it is a "chiral tubes" and $\mathrm{Y}$ takes a value between $0^{\circ}$ to $30^{\circ}$.

The value of $\mathrm{n}$ and $\mathrm{m}$ determine the chirality of a nanotube [Ref. Fig.4] and affect the corresponding optical, mechanical and electrical properties of the nanotube.

CNT can be either metallic or semi conducting, depending upon the chirality, which is applicable in the case of SWCNTS whereas MWCNTS are generally conducting in nature [5].

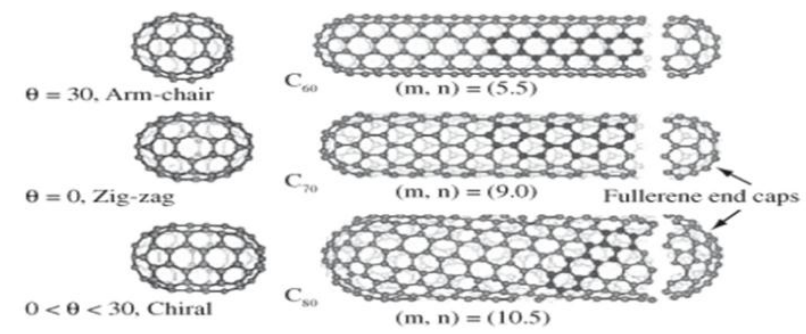

\subsection{Properties of CNTs}

Fig.4 - Three structures of SWCNTs: (a) armchair, (b) zigzag, (c) chiral Nanotubes[23]

CNTs possess many useful and unique properties such as:

- high electrical conductivity

- very high tensile strength

- highly elastic (18\% elongation prior to failure)

- high thermal conductivity

- low thermal co-efficient of expansion

- high flexibility i.e. can be bend without any severe damage

- high aspect ratio (length/diameter=1000)

- light weight

The strength of $\mathrm{sp}^{2} \mathrm{C}-\mathrm{C}$ bond provides amazing mechanical properties for nanotubes. The young's modulus of CNTs is very high(around 1TP) which is approximately five times the value of steel. The ultimate tensile strength of CNTs is around $63 \mathrm{GPa}$ which is around 50 times of the strength of steel [17]. 
Depending upon the structure, CNTs can be metallic or semiconducting. Some metallic CNTs have conductivity 1000 times greater than that of $\mathrm{Cu}$. CNTs are very high thermal conductors. It can transfer 6000 Watts per meter per Kelvin at room temperature $(\mathrm{Cu}-385 \mathrm{~W} / \mathrm{mk})$. The thermal stability of CNT is estimated to be $2800{ }^{\circ} \mathrm{C}$ in vacuum and about $750{ }^{\circ} \mathrm{C}$ in air [17].

\subsection{Application of CNTs}

Carbon nanotubes are applied in various fields of science and technology, which includes aerospace, drug delivery, energy technology, composite manufacturing etc. Due to recent energy crises which is related to oil based energy generation, the scientists around the world are working on alternate technologies for energy production like solar energy, nuclear energy, fuel cell technology but their cost and efficiency is poor. This energy crisis could be countered by using Carbon nanotubes as materials for solar plates which has higher energy absorption capacity, thereby providing a cleaner energy source. In bio medical area we use CNTs in different bio sensors. United States use CNTs in army jackets thereby enhancing the reliability of security equipments which results in lower loss of life. In these days we are using CNTs for water treatment also[18].

Synthesized CNTs are also used as reinforcement in Al based composites

\subsection{Synthesis Methods}

After discovery of Carbon nanotubes by Iijima, their properties have been found to be interesting and have several applications. CNTs are synthesized by several methods. The major synthesizing methods for the production of CNTs are as follows [4]:

1. Electric arc-discharge method

2. Chemical Vapor Deposition

3. Laser ablation method

\section{Chemical vapor deposition (CVD)}

Among several techniques of CNT synthesis available today, chemical vapor deposition (CVD) is most popular and widely used because of its low set-up cost, high production yield, and higher purity. CVD is versatile in the sense that it offers harnessing plenty of hydrocarbons in any state (solid, liquid or gas), this enables the use of various substrates, and allows CNT growth in a variety of forms such as powder, thin or thick films, aligned or entangled, straight or coiled nanotubes, or a desired architecture of nanotubes on predefined sites of a patterned substrate. It also offers better control on the growth parameters [11].

\subsection{CVD setup}

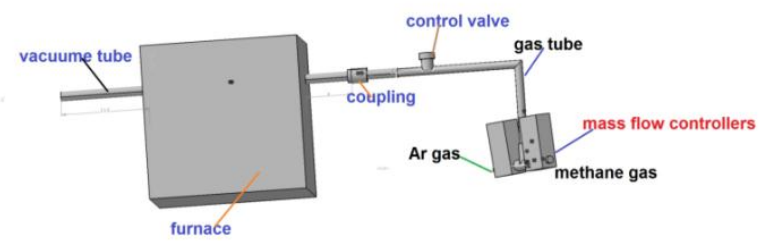

Fig. 5 Schematic diagram of CVD setup (model designed on CATIA-V5)

\subsection{Mechanism of CVD}

Fig. 5 shows a schematic diagram of the experimental set-up used for CNT growth by CVD method in its simplest form. The process involves passing a hydrocarbon vapor (typically for 15-60 min) through a tubular reactor in which a catalyst material is present at sufficiently high temperature $\left(600-1200^{8} \mathrm{C}\right)$ to decompose the hydrocarbon. CNTs grow on the catalyst in the reactor, which are collected upon cooling the system to room temperature.

In the case of a liquid hydrocarbon (benzene, alcohol, etc.), the liquid is heated in a flask and an inert gas is purged through it, which in turn carries the hydrocarbon vapor into the reaction zone. If a solid hydrocarbon is to be used as the CNT precursor, it can be directly kept in the low-temperature zone of the reaction tube. Volatile materials (camphor, naphthalene, ferrocence etc.) directly convert from solid to vapor, and perform CVD while passing over the catalyst kept in the high-temperature zone.

\subsection{Growth mechanism}

There are two growth mechanisms

1. Tip growth model

2. Base growth model 


\subsubsection{Tip growth model}

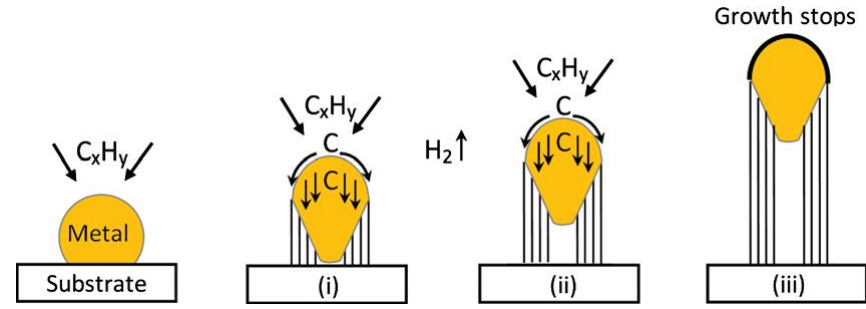

Fig. 6 Growth mechanism "Tip growth model” [11]

In Fig. 6, When the catalyst-substrate interaction is weak (metal has an acute contact angle with the substrate), hydrocarbon decomposes on the top surface of the metal, carbon diffuses down through the metal, and CNT precipitates out across the metal bottom, pushing the whole metal particle off the substrate. (As depicted in step (i)). As long as the metal's top is open for fresh hydrocarbon decomposition (concentration gradient exists in the metal allowing carbon diffusion), CNT continues to grow longer and longer (ii). Once the metal is fully covered with excess carbon, its catalytic activity ceases and the CNT growth is stopped (iii). This is known as "tip-growth model."

\subsubsection{Base growth model}

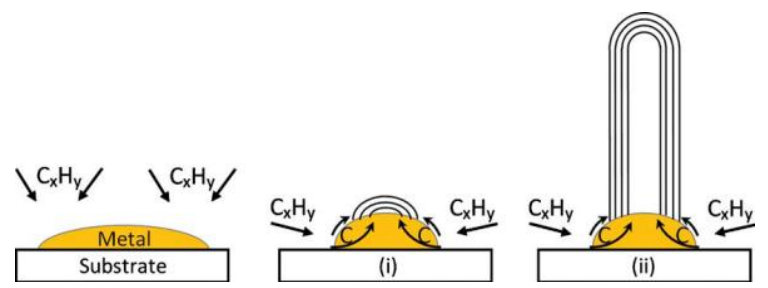

Fig. 7 Growth mechanism "Base growth model" [11]

When the catalyst substrate interaction is strong (metal has an obtuse contact angle with the substrate), initial hydrocarbon decomposition and carbon diffusion takes place similar to that in the tip-growth case, but the CNT precipitation fails to push the metal particle up; so the precipitation is compelled to emerge out from the metal's apex (farthest from the substrate, having minimum interaction with the substrate).

First, carbon crystallizes out as a hemispherical dome (the most favorable closed-carbon network on a spherical nano particle) which then extends up in the form of seamless graphitic cylinder. Subsequent hydrocarbon deposition takes place on the lower peripheral surface of the metal as dissolved carbon diffuses upward. Thus CNT grows up with the catalyst particle rooted on its base; hence, this is known as "base-growth model." [11]

\subsection{Precursors}

Carbon containing compounds that are used to synthesize carbon nanotubes, are called precursors. Different precursors for producing carbon nanotubes are,

Carbon mono oxide $(\mathrm{CO})$, Methane $\left(\mathrm{CH}_{4}\right)$, Ethylene $\left(\mathrm{C}_{2} \mathrm{H}_{4}\right)$, Acetylene $\left(\mathrm{C}_{2} \mathrm{H}_{2}\right)$, Benzene $\left(\mathrm{C}_{6} \mathrm{H}_{6}\right)$, Toluene $\left(\mathrm{C}_{7} \mathrm{H}_{8}\right)$, Ethanol $\left(\mathrm{C}_{2} \mathrm{H}_{5} \mathrm{OH}\right)$, plastics, etc

Table 1: List of different precursors with their phase and decomposition temperature [9]

\begin{tabular}{|c|c|c|c|}
\hline S No. & Precursors & Phase & $\begin{array}{c}\text { Decomposition } \\
\text { Temperature }\end{array}$ \\
\hline $\mathbf{1 .}$ & Methane & Gas & $\mathbf{5 0 0 - 8 0 0}$ \\
\hline 2. & Ethane & Gas & $550-640$ \\
\hline 3. & Acetylene & Gas & $1500-1800$ \\
\hline 4. & Ethanol & Liquid & $780-1085$ \\
\hline 5. & $\begin{array}{c}\text { Carbon monoxide } \\
\text { (with catalyst) }\end{array}$ & Gas & 700 \\
\hline 6. & $\begin{array}{c}\text { Carbon mono oxide } \\
\text { (without catalyst) }\end{array}$ & Gas & 2900 \\
\hline 7. & $\begin{array}{c}\text { Acetylene } \\
\text { (with catalyst- Fe) used } \\
\text { for MWCNTs }\end{array}$ & Gas & 700 \\
\hline
\end{tabular}




\subsection{Catalysts}

Generally transient metals $(\mathrm{Co}, \mathrm{Ni}, \mathrm{Fe}, \mathrm{Cu})$ are used as catalyst in CVD because of their melting point (In CVD, temperature range is $800-1200^{\circ} \mathrm{C}$ ) [16], so other metals like $\mathrm{Mg}, \mathrm{Al}, \mathrm{Na}, \mathrm{K}$ etc. will be melted. Transient metals will not form oxide layer over their surface so it can be used for longer time.

\subsection{Carrier gases}

We use $\mathrm{N}_{2}$, Ar as carrier gas because these are nonreactive gases. It does not react with catalysts and are easily available at low cost. We used Ar gas as the carrier gas.

\section{Purification of MWCNTs}

In CVD method we get MWCNTs that have number of impurities like dust particles, deposited carbon and metallic particles etc. to remove these impurities purification process is required.

\section{Treatment- 1}

The fine powder is treated with de-ionized water and is soaked for 3 hours and then it is dried in hot air oven.

\section{Treatment- 2}

The dried powder is treated with Toluene for 3 hours and the obtained CNTs are placed in a crucible for direct oxidation in air atmosphere at $650^{\circ} \mathrm{C}$ for 3 hours to remove carbonaceous materials.

\section{Treatment- 3}

The oxidized CNTs are treated with concentrated $\mathrm{HCl}$ for 24 hours and cleaned with water for 4 to 5 times to remove acidic nature of the CNTs and are dried in hot air oven

\subsection{Composite preparation}

\section{Al + CNTs composites}

We used Powder Metallurgy technique to prepare the $\mathrm{Al}+\mathrm{CNTs}$ composites. We added CNTs in pure Aluminum in different proportion like $0.5 \mathrm{w} \%, 1.0 \mathrm{w} \%, 1.5 \mathrm{w} \%, 2.0 \mathrm{w} \%$.

First we got MWCNTs by using CVD method, these CNTs were not so pure, so we purified them using various techniques. Those pure CNTs were used in the reinforcement of Al. Commercially pure aluminum was used as the matrix material. A mixture of CNT and aluminum powder (200 meshes) was ball milled at $200 \mathrm{rpm}$ for 5 min.

\subsubsection{Compaction of Al + CNTs}

We used Die molding (pressing) for AL + CNTs compaction. In this process we apply axial force to compress the powder of $\mathrm{Al}+\mathrm{CNTs}$ that is placed in a die between two rigid punches. The milled powder was compacted in a circular die with a load of $120 \mathrm{KN}$.

The schematic diagram of the die molding method is presented in the fig. 10

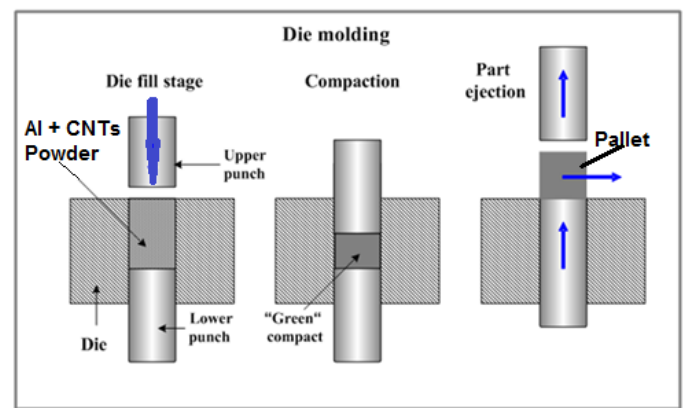

Fig. 10 schematic diagram of Die moldings (Pressing)

\subsubsection{Sintering}

During sintering of samples, we coated them with Alumina $\left(\mathrm{Al}_{2} \mathrm{O}_{3}\right)$. The coated billets thus obtained were sintered in an inert gas environment (nitrogen) for $45 \mathrm{~min}$ at $580{ }^{\circ} \mathrm{C}$ and finally hot extruded at $560{ }^{\circ} \mathrm{C}$.

\subsection{Optical microscope}

\section{Characterization Techniques}

Different samples are given- 
Sample1 - Pure Al

Sample 2 - Cupper Coated CNTs with Al reinforced Composites

Sample 3 - Nickel Coated CNTs with Al reinforced Composites

Sample 4 - CNTs reinforced Al composites

We used optical microscope to check the scratches and grain boundaries.

Sample 1

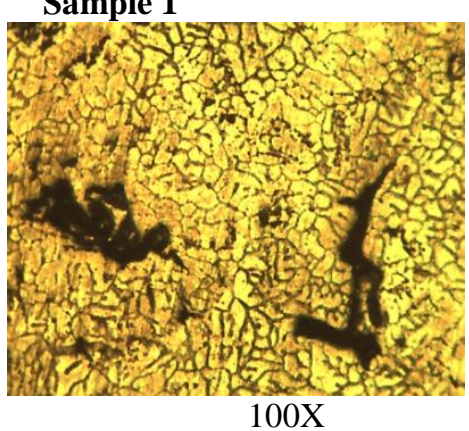

Sample 2

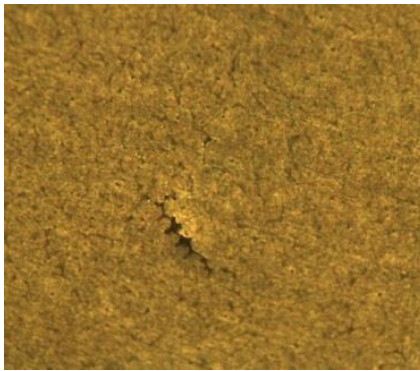

$100 \mathrm{X}$

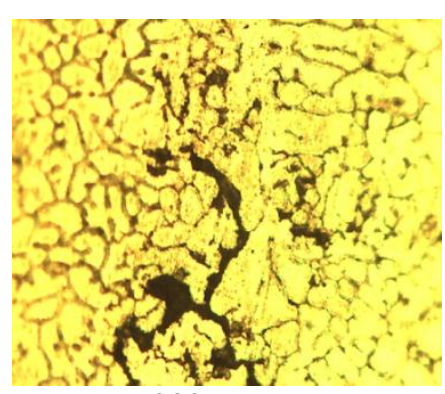

$200 X$

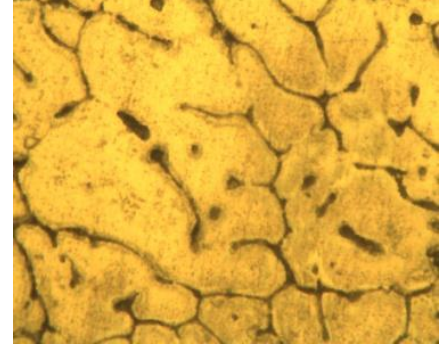

$500 \mathrm{X}$

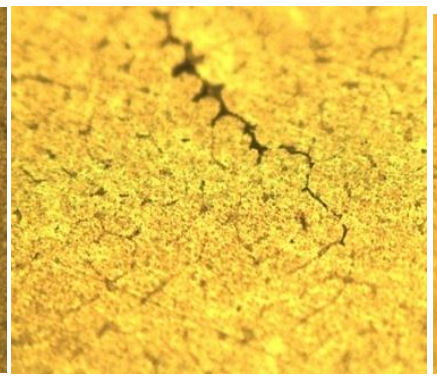

$200 X$

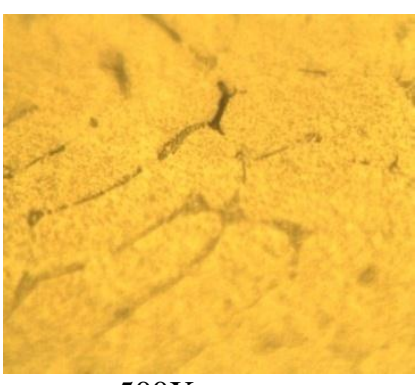

$500 X$

Sample 3
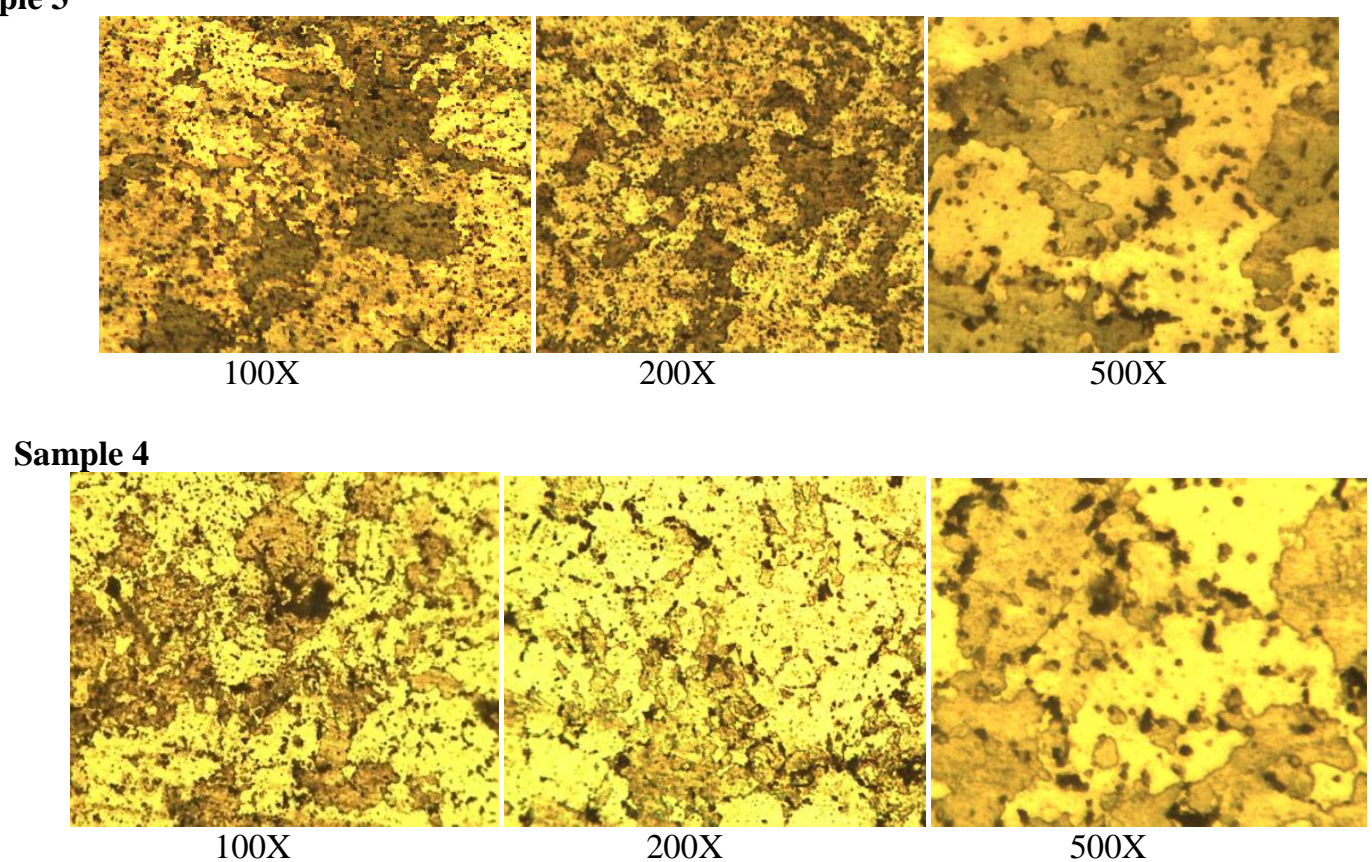

Fig.11. the microstructures of samples of $\mathrm{Al}, \mathrm{Al}$ with $\mathrm{CNT}$ and $\mathrm{Al}$ with $\mathrm{Ni}$ coated $\mathrm{CNT}$ s at various magnifications

\subsection{X-Ray Diffraction}

$\mathrm{XRD}$ is a powerful technique used to uniquely identify the crystalline phase present in the material and to measure structural properties of phases such as strain state, grain size, epitaxy, phase composition, preferred orientation and defect structure. XRD is nonconductive and nondestructive method, which makes it ideal for in situ studies. 
The crystalline material consists of series of atomic planes. When the X-ray incidents on atomic plane and gets diffracted at an angle $2 \mathrm{Y}$ it is known as the Diffraction angle. The diffracted intensity is measured as a function of $2 \mathrm{Y}$ and the orientation of the specimen, this yields the diffraction pattern. Crystal consists of planes of atoms that are spaced at a distance ' $d$ '. Any atomic plane can be uniquely distinguished by Miller indices. The d- spacing between (hkl) planes is denoted by $\mathrm{d}_{\mathrm{hkl}}$, and for cubic crystal, it is

$$
\mathrm{d}_{\mathrm{hkl}}=\mathrm{a}_{0}\left(\mathrm{~h}^{2}+\mathrm{k}^{2}+\mathrm{l}^{2}\right)^{1 / 2}
$$

Where $\mathrm{a}_{0}$ is lattice constant of the crystal.

When there is constructive interference from X-Ray scattered by the atomic planes in the crystal, a diffraction peak is observed.

The condition for constructive interference from planes with spacing $d_{h k l}$ is given by Bragg's Law [15],

$$
\lambda=2 \mathrm{~d}_{\mathrm{hkl}} \sin \mathrm{Y}_{\mathrm{hlk}}
$$

Where $Y_{\mathrm{hkl}}$ is the angle between the atomic planes and the incident $\mathrm{X}$-Ray beam. For diffraction to be observed, the detector must be positioned so that the diffraction angle is $2 \mathrm{Y}_{\mathrm{hlk}}$ and the crystal must be oriented so as the normal to the diffracting plane is co-planar with incident and diffracted beam.

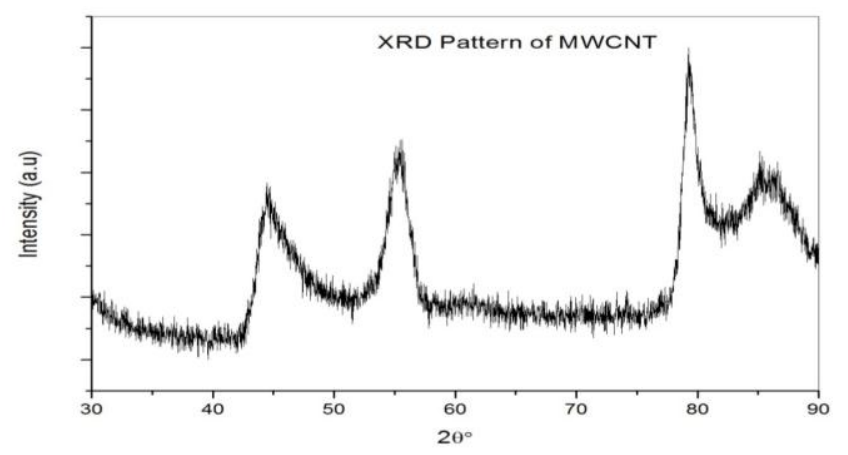

Fig.17 X-ray Diffraction pattern for Multi-walled carbon nanotubes (on experiment)

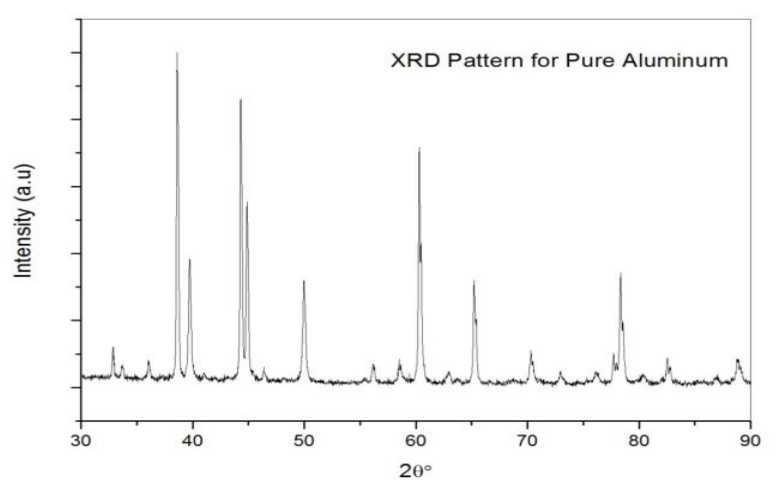

Fig.18 X-ray Diffraction pattern for Pure Aluminum (on experiment)

The diffraction pattern of pure Aluminum is compared with the reinforced Aluminum i.e. is CNT reinforced $\mathrm{Al}$ and with Copper coated CNT reinforced Al. This comparison helps us to know whether CNTs are mixed completely in the aluminum matrix or remain itself in the aluminum matrix.

The Weight percentage of CNTs in Aluminum matrix is

- $1 \mathrm{Wt} \% \mathrm{CNT}$

- $2 \mathrm{Wt} \% \mathrm{CNT}$

The Weight percentage of Copper Coated CNTs in Aluminum matrix is

- $\quad 1 \mathrm{Wt} \% \mathrm{Cu}$ coated CNT

- $2 \mathrm{Wt} \% \mathrm{Cu}$ coated CNT 


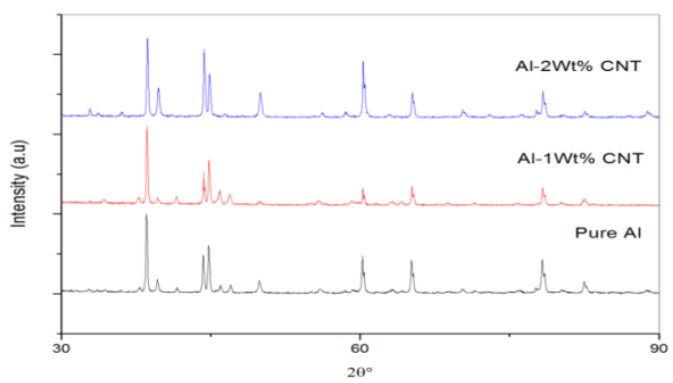

Fig.19 Comparing XRD Pattern with pure Al by varying Wt. \% of CNT (on experiment)

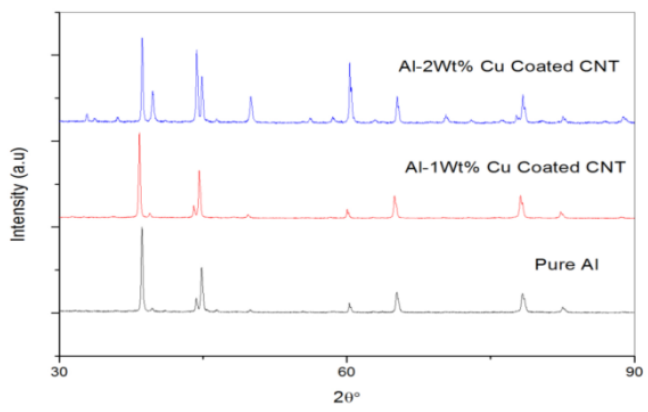

Fig.20 Comparing XRD pattern with pure Al by varying Wt. \% of Cu coated CNT (on experiment)

\subsection{Scanning Electron Microscope}

SEM is method of high resolution image of surface. The SEM uses high voltage beam electrons for imaging and gives topographical information. The advantages over SEM over light microscopy include much higher magnification (> 100000X) and greater depth of field up to 1000 times that of light microscopy qualitative and quantitative chemical analysis information is also obtained using an Energy dispersive X-Ray spectrometer (EDS) with SEM.

In the SEM a source of electrons are focused (in vacuum) into a fine probe that is incident over the surface of the specimen [Ref. Fig 9]. As the electrons penetrate the surface, a number of interactions occur that can result in emission of electron or photon from the surface. A reasonable fraction of electrons emitted can be collected by appropriate detector and the output can be modulated by the brightness of the cathode ray oscilloscope (CRT) whose $\mathrm{X}$ and $\mathrm{Y}$ input are driven in synchronism with the $\mathrm{X}-\mathrm{Y}$ voltages rastering the electron beam.

The principle images produced in the SEM are of three types, secondary electron image, back scattered electron images and elemental X- ray maps. Secondary and back scattered electrons are conventionally separated according to their energies $(<50 \mathrm{eV}$ - secondary electron, $>50 \mathrm{eV}-$ back scattered electron) [21].

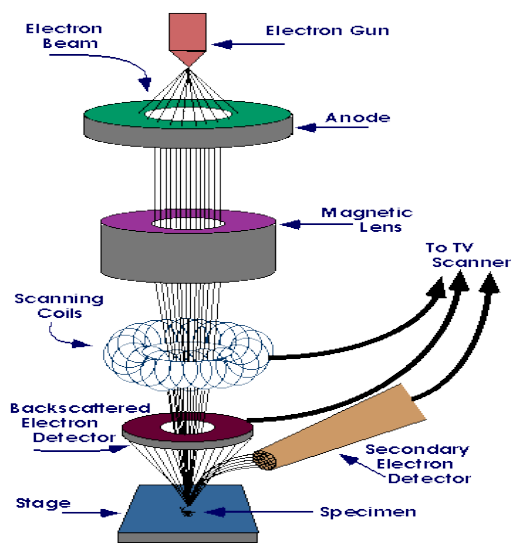

Fig. 9 Schematic diagram of Scanning Electron Microscope (SEM) [21]

\subsection{Micro hardness testing}

We test the hardness of pure $\mathrm{Al}$ and $\mathrm{Al}-\mathrm{CNTs}$ composites by using Vicker Hardness Test. In this test diamond is used as an indenter, having the form of a square based pyramid with an angle of $136^{\circ}$ between opposite faces. This is pressed into the flat surface of the test piece using a specified force, and the diagonals of the resulting indentation are measured using 
microscope. The hardness is expressed as a Vickers pyramid number which is defined as the ratio F/A, where $\mathrm{F}$ is the force and $\mathrm{A}$ is surface area of indentation.

$$
\mathrm{H}_{\mathrm{v}}=0.854 \mathrm{~F} / \mathrm{L}^{2}
$$

Where $\mathrm{L}$ is the average length of the diagonal is, $\mathrm{L}=1 / 2\left(\mathrm{~L}_{1}+\mathrm{L}_{2}\right)$

We prepared the different samples and check the hardness.

Table 2-5: Hardness values for Pure Al, Nickel coated CNTs, Cupper coated CNTs Al composites and Al-CNT Samples (on experiment)

\begin{tabular}{|c|c|c|c|}
\hline \multicolumn{4}{|c|}{ Hardness values for Pure Al, Nickel-Cu coated CNTs and Al-CNT Samples } \\
\hline \multicolumn{4}{|c|}{ Sample 1} \\
\hline S.No & D1 & D2 & HV \\
\hline 1 & 176.1 & 206.38 & 25.3 \\
\hline 2 & 193.3 & 198.32 & 24.2 \\
\hline 3 & 189.89 & 193.3 & 24.2 \\
\hline 4 & 177.49 & 177.79 & 26.6 \\
\hline 5 & 183.15 & 190.47 & 26.6 \\
\hline 6 & 191.44 & 189.89 & 25.5 \\
\hline 7 & 189.46 & 192.42 & 25.4 \\
\hline 8 & 186.79 & 189.07 & 26.3 \\
\hline 9 & 189.11 & 194.28 & 25.2 \\
\hline 10 & 194.28 & 193.08 & 24.7 \\
\hline \multicolumn{4}{|c|}{ Average value of hardness $=25.4$} \\
\hline \multicolumn{4}{|c|}{ Sample 2} \\
\hline S.No & D1 & $\overline{\mathbf{D 2}}$ & HV \\
\hline 1 & 87.4 & 87.4 & 108.01 \\
\hline 2 & 99.64 & 99.65 & 93.4 \\
\hline 3 & 97.83 & 95.15 & 99.6 \\
\hline 4 & 95.15 & 95.15 & 102.4 \\
\hline 5 & 91.86 & 93.09 & 108.4 \\
\hline 6 & 92.41 & 92.4 & 108.6 \\
\hline 7 & 130.91 & 139.78 & 50.6 \\
\hline 8 & 117.31 & 117.65 & 67.2 \\
\hline 9 & 177.68 & 176.34 & 44.3 \\
\hline 10 & 111.56 & 106.93 & 77.7 \\
\hline \multicolumn{4}{|c|}{ Average value of Hardness $=86.02$} \\
\hline \multirow{2}{*}{\multicolumn{4}{|c|}{ Table 4.}} \\
\hline & & & \\
\hline S.No & D1 & D2 & HV \\
\hline$\overline{1}$ & 85.27 & 88.96 & 122.2 \\
\hline 2 & 87.75 & 90.79 & 116.3 \\
\hline 3 & 86.86 & 86.28 & 124 \\
\hline 4 & 84.3 & 87.91 & 125.1 \\
\hline 5 & 84.9 & 86.58 & 126.1 \\
\hline 6 & 88.11 & 87.78 & 119.9 \\
\hline 7 & 85.82 & 86.86 & 124.4 \\
\hline 8 & 86.15 & 89.14 & 120.7 \\
\hline 9 & 83.01 & 86.93 & 128.4 \\
\hline 10 & 86.87 & 86.71 & 123.1 \\
\hline \multicolumn{4}{|c|}{ Average value of Hardness $=123.02$} \\
\hline \multicolumn{4}{|c|}{ Sample 4} \\
\hline S.No & $\overline{\text { D1 }}$ & D2 & HV \\
\hline 1 & 93.94 & 96 & 102.8 \\
\hline 2 & 101.47 & 95.11 & 96 \\
\hline 3 & 93.14 & 96.53 & 103.1 \\
\hline 4 & 96.21 & 97.5 & 98.8 \\
\hline 5 & 97.5 & 119.62 & 78.7 \\
\hline 6 & 95.48 & 98.32 & 98.7 \\
\hline 7 & 95.89 & 95.89 & 100.8 \\
\hline 8 & 99.62 & 98.64 & 94.4 \\
\hline 9 & 106.73 & 106.26 & 81.8 \\
\hline 10 & 99.02 & 112.94 & 82.6 \\
\hline
\end{tabular}




\subsection{Density measurement}

Density is the ratio of mass and volume. Relative density of solid or fluid is the ratio of density of solid or fluid to the density of standard fluid (Water).

The density of the immersed object relative to the density of the fluid can easily be calculated without measuring any volumes [22]:

$$
\frac{\text { density of object }}{\text { density of fluid }}=\frac{\text { weight }}{\text { weight }- \text { apparent immersed weight }} \text {. }
$$

Table 6: List of densities of Al CNTs composites (on experiment):

\begin{tabular}{|c|c|c|c|}
\hline Samples & Mass in air (gm) & Mass in water (gm) & Density g/cc \\
\hline 1 & 13.7229 & 8.6110 & 2.6845 \\
2 & 6.8234 & 4.2168 & 2.6177 \\
3 & 14.8173 & 9.5837 & 2.8311 \\
4 & 24.4115 & 15.6289 & 2.7795 \\
\hline
\end{tabular}

\section{Conclusions}

Chemical vapor depositions synthesized CNTs are purified and purified CNTs have more graphitic nature compared to unpurified CNTs.

We prepared the Al CNTs composites by using Powder Metallurgy technique. By using XRD we checked the mixing pattern of Al CNTs reinforced composites. Then, we compared the properties like Hardness, Density etc. and micro structures of CNTs reinforced Al composites, $\mathrm{Cu}$ and Ni coated Al CNTs composites with pure Al. We reinforced the Al with MWCNTs at different weight percentages. Hence on conclusion, Sample of pure Al's hardness is 25.4 but after reinforcing the hardness raised to 123.02[Ref table 2\&3]. The density of pure $\mathrm{Al}$ is $2.70 \mathrm{~g} / \mathrm{cc}$. after adding CNTs the variation of density has shown in table 6 .

\section{References}

[1]. A Thesis by Zhiyang Rong" Fabrication and characterization of carbon nanotubes for biomedical applications", (2008).

[2]. Xudong Yang, Enzuo Liu; Chunsheng Shi; Chunnian He; Jiajun Li; Naiqin Zhao; Katsuyoshi Kondoh "Fabrication of carbon nanotube reinforced Al composites with well-balanced strength and ductility" Journal of Alloys and Compounds 563 (2013).

[3]. Jianlin Li; Lianjun Wang; Tin He; Wan Jiang C A R B ON 47 (2 000 9) 1135 -1 140.

[4]. Iijima S.; Helical microtubules of graphitic carbon. Nature (1991); 354:568.

[5]. http://people.bath.ac.uk/t1258/Nanotechnology/Types.html

[6]. Ebbesen TW; Ajayan PM.; Large-scale synthesis of carbon nanotubes. Nature (1992); 358:220-2.

[7]. Bryning MB, Milkie DE; Islam MF; Kikkawa JM; Yodh AG.; Thermal conductivity and interfacial resistance in single wall carbon nanotube epoxy composites. Appl Phys Lett (2005); 87(16):161909.

[8]. R.S. Ruoff; D.C. Lorents Carbon; 33 (1995), p. 925

[9]. R. George, K.T. Kashyap; R. Rahul; S. Yamdagni; vol. 53, (2005).

[10]. Hiroki Kurita1; Hansang Kwon; Akira Kawasaki; J. Japan Inst. Metals, Vol. 75, No. 4(2011).

[11]. Mukul Kumar* and Yoshinori Ando, J. Nanosci. Nanotechnol. 10, 3739-3758,(2010).

[12]. M. S. Dresselhaus; G. Dresselhaus; K. Sugihara; I. L. Spain; H. A. Goldberg; Graphite Fibers and Filaments Springer-Verlag, $\operatorname{Berlin}(1988)$

[13]. Wei, T.; Fan, Z.; Luo, G.; Wei, F.; Zhao, D.; Fan; J. Mater; Res. Bull. (2008), 43, 2806-9.

[14]. Thess, A.; Lee, R.; Nikolaev, P.; Dai, H.; Petit, P.; Robert, J.; Xu, C.; Lee, Y. H.; Kim, S. G.; Rinzler, A. G.; Colbert, D. T.; Scuseria, G. E.; Tománek, D.; Fischer, J. E. and Smalley; R. E. Science (1996), 273, 483.

[15]. Wu, B.; Hou, S.; Yu, M.; Qin, X.; Li, S.; Chen, Q. DNLM, (2008), In Press.

[16]. Zhang F; Shen J; Sun J; Zhu YQ; Wang G; McCartney DG; Carbon (2005);43(6):1254-8

[17]. Wikipedia Internet Encyclopedia, www.wikipedia.com.

[18]. Treacy; M.M; Ebbesen; T.W.; et. al; "Youngs Modulus of SWCNTs", Physical Review B, 58,p20 (1998).

[19]. Nam Seo Kim; Y T Lee; J Park; H Ryu; H J Lee; S Y Choi; J Choo; F Rohmund; J. Phys. Chem.B106, 9286 (2002).

[20]. P Chen; X Wu; J Lin; K L Tan; Science285, 91 (1999)

[21]. http://www.purdue.edu/rem/rs/sem.htm

[22]. http://en.wikipedia.org/wiki/Archimedes'_principle

[23]. http://cnx.org/content/m22580/latest 